
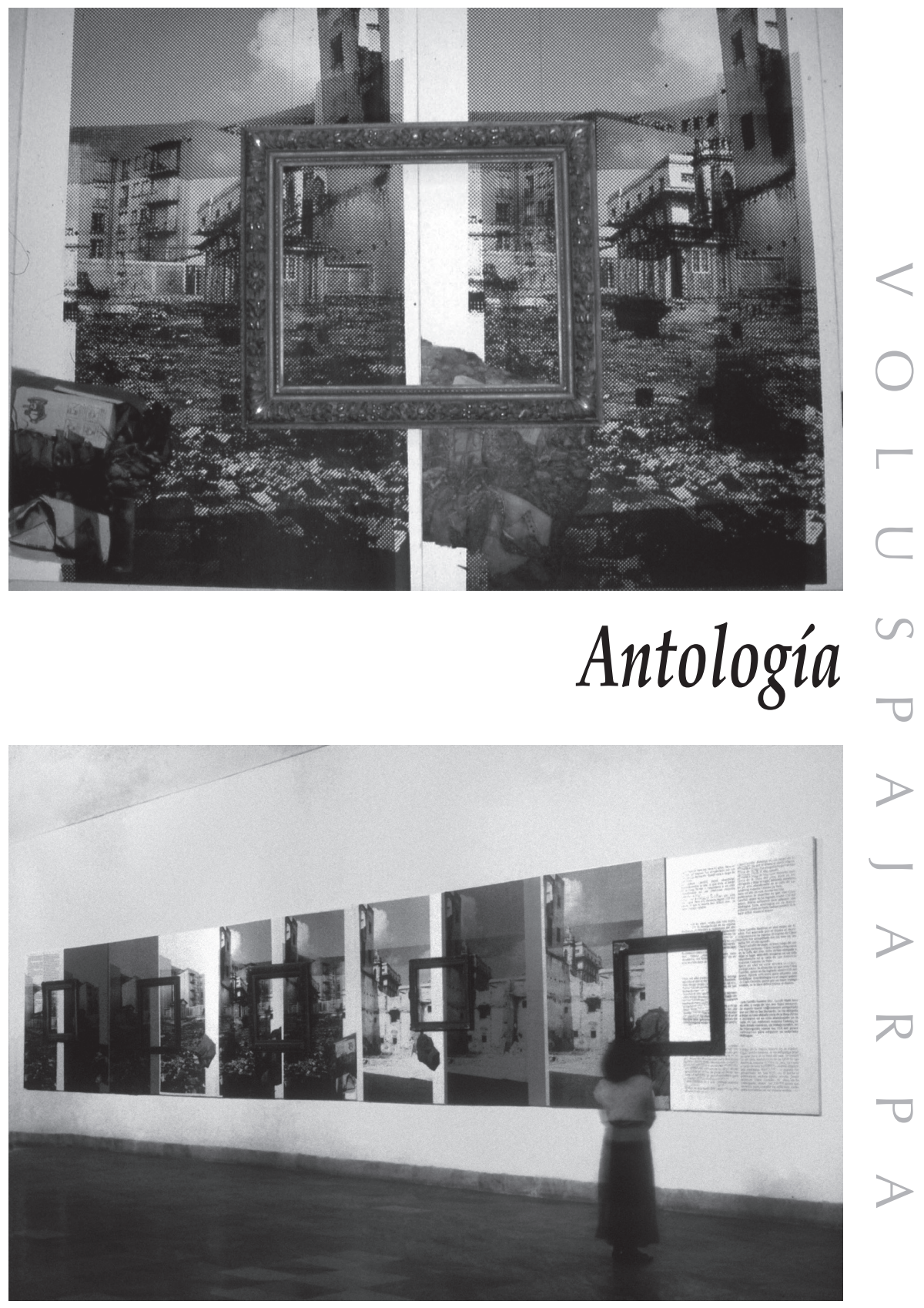

Santiago /La Habana, Serie de los Eriazos

IV Bienal de La Habana, Convento Santa clara, La Habana, Cuba, 1997.

Políptico. Serigrafía, óleo y objetos sobre tela. $2.40 \times 12.00$ m. 


\section{Filigranas poéticas / asedios nómades a la poesía de mujeres mapuche $y$ de origen mapuche}

Fernanda Moraga ${ }^{1}$

Gran parte de la poesía de mujeres mapuche y de origen mapuche, nos introduce en territorios de una práctica cultural que contribuye sustancialmente a una concepción de la escritura como práctica política del cuerpo, en cuanto no hace concesiones a los estereotipos culturales. Libera ciertas categorías impuestas a la poesía mapuche, en relación a un origen y a un anclaje "étnicamente" correcto. Las poetas, en general, desbordan unos rastros corporales, subjetivos y poéticos que van erosionando el corsette de las identidades de género y culturales, manifestando una plural posición de cuerpos de y en la cultura. En este sentido, los poemas se abren y se enfatizan ante la lectura, como un insubordinado espacio de posibilidades corporales múltiples, tales como: la locura, el erotismo, los cuerpos lésbicos, las nomadías, los espacios privados, las mixturas y la pérdida de la lengua que decía y que aún habla sin cesar, el cuerpo urbano, la "iletrada" y por supuesto, la relevancia de una cultura y una historia mapuche antigua y actual. Todas éstas, son corpografías que desafían las dominaciones del referente identitario, cualquiera sea su dimensión cultural. En este sentido, esta pequeña selección de poesía de mujeres mapuche y de origen mapuche, se despliega fundamentalmente dentro de un calidoscopio que señala las trazas escriturales de ocho poetas. Algunas de ellas presentan su escritura en dos versiones, una en mapuzungun y otra en español, gesto que sabemos no es silencioso, sino que corresponde a una enunciación plural, política y estética, la que en esta recopilación se ha respetado. La selección no ha sido simple, porque sabemos que la producción actual de poesía de mujeres mapuche es mucho más amplia y diversa.

Esta poesía escrita tiene su genealogía inaugural en los primeros ül (cantos) de mujeres (especialmente los llamekan y los machi $\ddot{u} l^{2}$ ), que fueron transcritos tanto al mapuzungun como al español, a fines del siglo XIX y principios del siglo XX. Con 
respecto a la poesía actual, se inicia en el año 1977, con la publicación del libro Horas de lluvia de Sonia Caicheo, con el cual se pone en circulación, en esos momentos, un nuevo cuerpo y una nueva palabra poética dentro de un restringido sistema literario chileno, debido a la dictadura de Pinochet. A partir de esta apertura poética, sin duda en y desde el margen, las mujeres mapuche y de origen mapuche han dado continuidad a esta práctica discursiva, principalmente, desde fines de los 90, configurando un importante corpus de producción poética. En general, esta poesía posiciona una comunidad polifónica de voces y cuerpos escriturales, que abre un abanico de disposiciones poéticas que van desde una intensa (re)unión con lo cosmovisional-ancestral y espiritual, hasta prácticas desmitificadoras de la cultura y de unas sujetos de esa cultura, problematizando así la enunciación de los poemas. Dentro de este contexto de producciones textuales, la poesía escrita de mujeres mapuche se sitúa como una práctica cultural enhebrada a condiciones de género, históricas y sociales, que recorren el tiempo ancestral, a la vez, que el tiempo de colonización del cuerpo (pasado y actual). Es decir, son poetas que escriben desde una conciencia de género y etnicidad con diferentes grados de aproximación y distanciamiento de la cultura mapuche.

En este sentido, se puede mencionar que existen a lo menos tres estrategias de enunciación que circulan por los diferentes textos y que envuelven marcas temáticas que han sido y siguen siendo parte de la visión de mundo mapuche: la tierra, la ritualidad y la violencia, las que aparecen con diversas desenvolturas en los poemas. Por un lado, están aquellas producciones poéticas que se instalan en una memoria ancestral, haciendo surgir un sentido de nostalgia por lo que se perdió y no es posible recuperar. En este lugar, las disposiciones escriturales recurren fundamentalmente al origen ancestral, espiritual y territorial no contaminado e idealizado de la cultura mapuche. A partir de aquí se originan cruces importantes con una segunda posible enunciación, es decir, con la emergencia de un pasado reconstituyente que se superpone al presente intoxicado, representado dentro de la escritura como "un mundo posible" de la cultura. Dentro de esta línea, me parece, se encuentran las escrituras de Cecilia Nahuelquín y María Huenuñir que aparecen en esta antología. 
En un tercer trazo de estrategia discursiva de las poetas, surgen escrituras que se apropian explícitamente de los recursos y técnicas de la poesía moderna (como afirma el poeta Jaime Huenún) y que con diferentes matices, presentan subjetividades culturales en tensión, asumiendo experiencias, muchas veces, colmadas de contradicciones, las que emergen, justamente, como posibilidades de ruptura con la insistencia colonialista de hacer desaparecer forzadamente cuerpos culturales que tienden a la fuga del sistema dominante. Dentro de este territorio se movilizan las escrituras de Maribel Mora Curriao, Roxana Miranda Rupailaf, Ivonne Coñuecar, Mariela Malhue, Adriana Paredes Pinda y Liliana Ancalao, presentadas en esta compilación poética.

Es importante mencionar que en esta antología existen ausencias fundamentales respecto a la incorporación de otras poetas, las que por falta de espacio no han sido incluidas, como por ejemplo, Miriam Torres Millán, Graciela Huinao, María Teresa Panchillo, Rayén Kuyeh, María Isabel Lara Millapán, Jacqueline Canihuán, Faumelisa Manquepillán y por supuesto Eliana Pulquillanca, entre muchas otras.

En lo fundamental, por un lado, el (mi) criterio de selección está situado en la escritura que, con intención, surge políticamente mestizada, fronterizada, tensionada, es decir, problematizada. Por otro lado, me interesa también señalar, muy brevemente, otro escenario de producción poética mapuche, como es la poesía de Cecilia Nahuelquín y de María Huenuñir. Ambas, utilizan un lenguaje directo, muy cercano a la oralidad y con una intensa proximidad a una tradición fundamental del pueblo mapuche.

Es imprescindible la insistencia y la importancia de leer en otras y diferentes direcciones, porque los poemas de esta selección, en su sustrato de objetos y/o producciones culturales, destruyen disposiciones normativas y su prefijado atributo de identidad se desmorona; para hacerse híbridos, fronterizos. Son, por lo mismo, objetos cargados de contenidos y agenciamientos corporales siempre procesuales, en movimiento hacia fuera y hacia dentro, interculturales e intraculturales.

Al hablar de escrituras fronterizas me refiero a que, por un lado, las tramas contextuales actuales de esta poesía no corresponden a territorios geográficos dados, a lugares raigales, sino que son más bien escenarios poéticos que proyectan y construyen el espacio nómade que se despliega a través de la lectura de un poema a otro y 
de una poeta a otra, hacia (des)bordes experienciales no fijos. La metáfora siempre es el movimiento que trae consigo un importante síntoma vincular con elementos culturales que arraigan el desarraigo y sólo la escritura puede fijar lo no fijado. A partir de este sentido abierto de lectura, emerge un cierto carácter migratorio de este breve registro de poesía de mujeres mapuche y de origen mapuche: los poemas se manifiestan de un lugar y se continúan hacia otro. Aunque sin duda hay un registro articulatorio, el que se hace visible en su permanente circulación de un cuerpo ancestral a otro, de una memoria a otra, de una subjetividad a otra, de un travestismo a otro... además, pero dentro del mismo tejido de un movimiento transhumante y vinculante dentro de los textos, los empalmes de un efecto de oralidad o estrategia dialógica de algunos de los poemas se distiende no como tipicidad coloquial, sino como acto de habla escritural: la voz es intervalo y continuidad, es acontecimiento y encuentro, para conformarse como signo insubordinado de escritura.

Sin duda, esta escritura nos presenta escenas de la sedición en diferentes sentidos. Por ejemplo, en las escrituras de Maribel Mora Curriao, de Roxana Miranda Rupailaf e Ivonne Coñuecar surge, de diferentes maneras, una consistente transformación genérica, la que se plasma a partir de subjetividades que se despliegan a la vez, masculinas y femeninas. Al reenfocar este territorio femenino y masculino, dentro del contexto general y actual de producción poética de mujeres, en primer lugar se produce una nueva fractura al sistema sexo genérico impuestos por las conspiraciones hegemónicas, respecto a la separación dicotómica de los géneros y de los sexos. Por otro lado, esta construcción de identidades de los géneros establece una diferente posición de la experiencia en la poesía de mujeres en general. Esto porque, aunque en la práctica poética de las mujeres los lugares binaristas de sexo y género se han destruido; el sustancial quiebre y aporte de esta escritura en este sentido, es la instalación de un sujeto femenino y masculino a la vez, que se construye y se desenvuelve a partir de otros códigos, experiencias, memorias y agenciamientos. A través de ello, el abanico de producciones de mujeres y de la poesía en general se multiplica aún más, activando una autoridad y una autoría, junto a una propuesta poética diferente e imprescindible. Incluso, también el lugar del femenino indisciplinado, se enfatiza aún más en los cuerpos implícitamente lésbicos de los textos de Roxana Miranda e Ivonne Coñuecar. 
Frente a esto se puede advertir el peligro que corre esta práctica poética, si ciertas lecturas académicas y no académicas, se instalan en un relato "determinista" en el cual se espera, finalmente, que la práctica poética mapuche y de origen mapuche (y el/la sujeto poético/a de esa práctica) "contextualice" todas sus correspondencias culturales. Estas lecturas y visiones clasificatorias, establecen nuevas demarcaciones hegemonizantes, donde a unos se les asigna la misión de reivindicar su "diversidad" o su "diferencia," mientras otros se reservan el derecho de formalizarla y relatarla. Quizás y a modo de reflexión ante este peligro, haya que entrar en la bisagra de la experiencia biográfica-cultural con el mundo simbólico de los textos, la sociedad y la historia mapuche y sus múltiples sentidos y vinculaciones, desde una perspectiva de lectura que haga trabajar las significaciones. Perspectiva que siempre debe intentar desplazar, perturbar y molestar las naturalizaciones prearmadas, ya que estas consignan las categorías de género y de las identidades a modelos únicos y tradicionales de la experiencia. De este modo, no se debe perder de vista que las diferentes identidades, entre ellas las de género, de clase y de etnia están señaladas por la multiplicidad de posiciones de sujeto que constituyen al y a la sujeto, desde donde éste y ésta, pueden dar sentido a la realidad como un proceso relacional de significaciones y resignificaciones.

Evidentemente, esta selección de poesía es una compilación inconclusa, puesto que tengo la clara comprensión de que nada se cierra en ella, pero al mismo tiempo, pienso también, que estas trazas poéticas despliegan una oportunidad de valorar un sustancial y fértil escenario de escritura de mujeres, materia escritural que, sin duda, empuja a repensar las relaciones entre género, culturas y poder. 
Maribel Mora Curriao3 (Panguipulli, 1970), profesora de Castellano y poeta de origen mapuche-pewenche. ${ }^{4}$ Mantiene un libro inédito, Perrimontún $n^{5}$. Muchos de sus poemas han sido publicados en diferentes antologías y revistas, tanto en Chile como en el extranjero. Actualmente, realiza el Doctorado en Estudios Americanos en la Universidad de Santiago de Chile y reside en Santiago.

\section{Voces extraviadas}

Me habita el delirio. Encendido el corazón bajo la luna, he debido cobijarme en mi kupalme ${ }^{6}$. Vacío de alma. Tierras sin espesura. Lo demás se pierde en el parpadeo de la historia. Pero los abuelos aún nos sueñan desde las montañas. Por eso escribo estas palabras. También por los hijos y los hijos de los hijos. Mañana serán del mundo.

Afuera los días pasan, la escritura nos detiene. Puro anhelo estas palabras, leves, mustias, átonas, nostalgia de praderas y de preces. ¡Ah! la poesía - esa vieja y desesperada paciencia- no me empuja ni me levanta, no me sueña ni me busca. Las visiones sí, las voces perdidas, kvtralwe ${ }^{7}$ encendido para espantar el miedo.

Manuela Colipe, ${ }^{8}$ abuela mía, madre de mis sueños. Manuel Curriao, voces oscuras de linaje extraviado. María Luisa Benavente en el cruce de las sangres. Juan Colipe Nancuvil, ${ }^{9}$ Bartola Gineo, ${ }^{10}$ José Ignacio y Belarmino Chiguay, ${ }^{11}$ Margarita Curriao y tantos otros y tantas otras en esas palabras-bosque. Aún podemos escucharlos ¿aún nos sueñan? ¿Todavía las vertientes acuden a su llamada? ¿Todavía las montañas?

He visto tu corazón pintado en las estrellas, latiendo inconfundible en la corola de las flores. ¿Si no estuvieras? ¡Ah!, si no estuvieras madreabuela: ¿cómo respiraría el mundo?

Nos nombraron brujos, indios, nada. Siervos, trofeos, vencidos en guerra, bajo el yugo de la espada y la palabra.

Ya no hay Treng Treng para huir de Kai Kai Vilu, ${ }^{12}$ el mundo entero es una sola planicie. El likan ${ }^{13}$ hipnótico me quema por dentro, posesa, perdida, sin el corazón, sin aliento. Por eso debimos ocultarnos en el monte de la palabra poética: maraña y espesura, delirio sin retorno, pérdida, pálpito agónico, canto, corazón y aire...

\section{Del libro inédito Perrimontún}

\section{Aquí estoy hermanos}

Nunca fue el viaje mi motivo, nunca abandoné estas tierras benditas, malditas, 
aquí estoy hermanos

atada a este suelo

que nunca nos bendijo.

Levanto la cabeza del polvo

de las generaciones.

Recojo mis huesos.

Nadie tiene nada

que decirle a mi noche.

La ira de los siglos

aplastando mis hombros.

Recojo mis sueños,

la mirada inclemente

de las sombras.

Nada puede contra

las premoniciones de hambre,

el gusano en la semilla

royendo lentamente

nuestra suerte.

Dame una razón

para seguir la ruta

un secreto

para evitar el cansancio

que a menudo acomete a mis piernas

y desfila por el resto de mi cuerpo.

Tengo miedo de mí misma

y de la muerte

y de mi espíritu salvaje aún

entre los que quedamos vivos

$\&$

Ven

mira la oscuridad

en mis ojos

y bebe con lentitud

el misterio en mis cabellos.

Desnudo el saber de mis labios

mira el sello de mi cuerpo,

pero no levantes el velo

de mi soledad sin memoria.

(del poema "Tuwin malen ${ }^{14 \prime)}$ 
$\&$

¡Madre mía

machi $^{15}$

ten piedad de mí!

espíritu sagrado

¡Abandona esta piel oscura!

Estos huesos yertos

no pueden ser tu casa

Estas palabras no pueden ya

decir tu canto.

El río del cielo llevará

mis cabellos

cortados

en señal de sacrificio

meulen $^{16}$ dispersará las plegarias

en ciudades paridas

como visiones.

Carne

y fuego

los signos de mi vientre

el cáliz que redime la blasfemia.

(del poema "Laberintos")

$\&$

IX

A la deriva a las seis de la tarde supimos nuevamente del mundo, no recordábamos la fecha de la partida ni la oculta razón de este naufragio. ¿Qué dios qué monstruo cavó nuestro destino? preguntábamos al oleaje desbordado. El horizonte como siempre en estos trances no era más que un punto en el vacío y el cielo una inmensa sábana gris que amenazaba descolgarse.

Nos volvimos entonces hacia la lejanía tratando de adivinar un Norte. Sin saber por qué ni cómo alzamos nuestras manos y en lenguas perdidas dijimos antiguas oraciones hacia oriente.

Apareció entonces un promontorio en el horizonte, la montaña y el valle desfilaban ante nuestros ojos. ¡Es la Atlántida! -dijimos- ¿o la isla de los muertos? ¿Vendrá Ulises, Sumpall ${ }^{17}$ o Jesucristo? Ante nosotros 
la historia persignada por el éxodo y un babélico idioma coartándonos los sesos.

Mañana volveremos, mañana -susurrábamos-agotados de la locura.

$X$

Años más tarde recordaríamos el mar y la tierra naciendo en el horizonte. Todos callábamos nuestras visiones. ¿Quién daría fe de la gran sierpe que salvó nuestras barcas?

(del poema "Naufragios")

\begin{abstract}
Roxana Miranda Rupailaf ${ }^{18}$ (Osorno, 1982), Profesora de Lengua Castellana y Comunicación y poeta de origen mapuchehuilliche ${ }^{19}$. Ha publicado el libro Las tentaciones de Eva (2003), con el que obtuvo el primer lugar en la categoría príncipe del concurso de poesía Luis Oyarzún. Pronto será publicado por Lom Ediciones, su libro Pu llimeñ ñi rulpázuamelkaken/Seducción de los venenos. Muchos de sus poemas han sido publicados en diferentes antologías y revistas chilenas y extranjeras. En la actualidad, realiza el Magíster en Literatura en la Universidad Austral de Valdivia y vive en Osorno.
\end{abstract}

Del libro Pu llimeñ ñi rulpázuamelkaken/Seducción de los venenos

Akúkayealu nga tróyzüngu

fey wutrúnentufin tichi nüpüng tañi ngépüle.

Tüfá ta ngenóneyen wiríkameken

welúkintumeken

tüfichi pu wakápüle ruménefilu fachi kuykúy engün,

chew ta allkéñngewenomum mamákün,

wirár may nga mületúy,

tüyéchi waykí ñi wirár ücháfkonkülelu kazímu ngatí

mollfüñ mu zichünefilu

tichi pu püllómeñ

ináyawületew ta iñché engün.

Wiríkameken langümnewün ta iñché llengá, pengélmeken,

ngülá allféñmekel chew tañi pepi ngümáyal

fey trayáytükupuam fentrénke ruku mew. 
Pütrün ngellípun may truürün mew.

Wiríkameken llíwküzenmalen ñi pu ngé.

Se cumple la profecía

$y$ derramo la tinta por los ojos.

Escribo sin aliento

distrayéndome

en las vacas que atraviesan este puente,

en donde ya no se oyen mugidos,

sino gritos,

de una lanza clavada en la costilla

que señala con sangre

las muertes

que seguirme.

Escribo masacrándome,

mostrando,

abriendo llagas en que llorar

$y$ golpear en tantos pechos.

Plegaria en los murmullos.

Escribo con velas en los ojos.

$\&$

Filu: Kimniey welu, Dios chuchí antü íwümefilmi nga, ngülá tripayay tamün puke ngé fey diosesküchiletugaymün, epéfill kimlu, kümékemayew wezáke ngünén

("Génesis," capítulo III, versículo 5)

Ifínge chi kulúy

anay zakín.

Nentunge kewün -kelü

ta epu lewléw mew.

Ünántükuwnge chi ilómew

fey ta müzákünufe chi kozáy

ziwíllkünufiel chazí engü llengá.

Lümüymunge chi üykülechi pu fün

fey pengélelfe ta apíllzuam

tüyéchi pu wümáwküleyelu. 
Serpiente: Sabe empero, Dios que en cualquier tiempo que comeréis de él, se abrirán vuestros ojos y seréis como dioses, conocedores de todo, del bien y el mal

(Génesis, capítulo III, versículo 5)

Come la manzana

mi querida.

Suelta baba -rojo

en las dos llamas.

Muérdete a la carne

y haz el jugo espeso

mezclándolo con sal.

Devórate los frutos en fuego

y muéstrale el deseo

a los que duermen.

$\&$

\section{Filu ñi ketró ülkantun}

I

Aylla küyen nga niékefin

ka küla nga amúlken

entúñmayafiel ñi nengüm,

katrügafiel

tañi puke chang mew.

Tripáyal nga pu filu

traríntükuneñmatew tañi küllché ñi puke ngémew engün.

Fentrén mollfüñ kaynga, ka fentrén wirar

ta tripáyal engün rafráfküyawulal ñi lingár kalül.

Atrérküli nga ñi puke filu

chümpólkülen tañi púkalül mew.

Ñüküf chew tañi tremümkemum

ka femngéchi tañi tremkémum. 
Mellúzün mollfüñ eyütumekey filu ketró ülkantun

(García Lorca)

Chümpóluwün tañi puke trülké mew mafülün tañi külen

tüyechi pu ngüyón püle.

Lümükünun ñi kewün.

Üyechi fentrén pu funápuwe ñi zuam lüfí chi pütra.

\section{Muda canción de serpiente}

I

Nueve meses las albergo

$\mathrm{y}$ tres son los que demoro

en sacarles el ritmo,

en cortarlas

de mis piernas.

En salírseme serpientes

con mis tripas atadas a los ojos.

Tanta sangre, y grito

para que salgan a arrastrar su cuerpo blanco.

Frías mis serpientes

enrolladas adentro de mi cuerpo.

Silencio en que me crecen

y en que crezco.

II

Sangre resbalada gime muda canción de serpiente

(García Lorca)

Me enrollo en mis pieles

me abrazo la cola

en los rincones. 
Me trago mi lengua.

De todos los venenos

arde el vientre.

$\&$

VII

Tüfachi willímapumu élkünukan müten chew tami pemufiel püróntükumeken ñi longko ta trokür mew.

Tüfa ta kizúkünuen may petu kowlu ta iñché

fey nga witrúamuletun kurüke lewfü mew

trémpüraletun llozkontu mew

fülümtükuluwün pu kullíñ mew ngatí

chumkáwnorume kimnógalu engün chémngen ta iñché.

Alürupachi ka nüpüngküchi wün mew

élkünuen

tañi fotráwkünuwal

fey ta nomnómnegal pülü kaynga.

VII

Déjame en este sur en que me encontraste

anudando mis cabellos a la niebla.

Déjame en este instante en que me vuelvo agua

y me voy por ríos negros

y me crezco en los pantanos

y me doy a los animales

que nunca sabrán de qué soy.

En boca ancha y pegajosa

déjame

serme barro

y llenarme de moscas.

(del poema "Alümapulen llellipín

tañi pu llawféñ engün" / Ritual de la ausencia

y sus sombras") 
Ivonne Coñuecar ${ }^{20}$ (Coyhaique, 1980), periodista y poeta de origen mapuche-huilliche. ${ }^{21}$ El año 2008, publicó Catabática, primer libro que compone una trilogía, junto a Anabática y Adiabática (ambos inéditos). Algunos de sus poemas han sido publicados en antologías y revistas. Ha recibido menciones y distinciones por su producción poética, además de haber sido becaria de la Fundación Pablo Neruda. El año 2009 inicia el Magíster en Literatura en la Universidad Austral de Valdivia, ciudad en la que reside.

Del libro Catabática (2008)

catabática la ausencia/ deste/ mi regreso

signos

para nombrarme

siglos

que demoré/ vivía

porque movían sus lenguas y sus bocas porque

no querían hablarme porque nadie me esperó

a la otra sí

diecisiete años rompiendo vidrios para cortarse las venas

y celebrar The rock star mito's

pero no regalé nada/ ni un pedazo de mi/ ni gritos

ni grietas

recordé entonces que ya no

que la muerte se lo había llevado que mi Patagonia

que mi tierra que mi niñez

esta fisura por donde el viento silba/ serena el latido

abisal/ deste/ mi estropajo corazón

desta/ espera sin sentido/ deste

volver pensando que era antes

dijeron que me lo merecía pero que ya no

$\&$

todo se duele en la nocturna boca

llena de colmillos resplandecientes

III

justo aquí te pierdo/ huracanes roban el cabello de tu niña/ infancia en bosque de caricaturas fuimos/ juega

el destierro con la memoria/ erosionada la cordillera mírame las grietas/ justo aquí nos repite con voz 
huilliche/ tú y yo sabremos resucitar justo aquí/ ni en la indeleble huella del dolor/ ni en cicatrices se muere

el arrepentimiento teje su lejanía por pasadizos secretos / te canto con ritmo de eluwun 22 / tú y yo sabemos

que justo aquí la muerte cansada de despedidas

\section{me invita porque no sabe de heridas}

\section{VI}

conocí a mi madre por las madres que repetían nombres que no me llamaban/ a mi madre se le olvidó

nombrarme y yo en mi cojera no puedo/ en mi ceguera no la vi jamás cuando me hicieron caminar hasta

el cementerio y yo no, yo ya no recuerdo cómo se camina, recuerdo cómo se grita/ cómo se punza el pecho

como no hay consuelo y evito, evito que me calmen/ ánima atravesando la puerta ánima cruzando la

calle justo aquí, ánima vagula blandula en la ciudad de los no perdones y noches gélidas

la ciudad en la que crecimos y no/ juguemos al escape, me alejo de la piel ajena

\section{Coincidimos todos como hermanos de distinta madre} (del poema "Eluwun")

$\&$

vamos, vamos que te la susurro despacito/ la ciudad aglomerada y mi historia sin verbos/ despiértame

la herida, aprende la cura de su gran costra/ cotidiano hábito de remendar el corazón, mi piel tan débil

¿qué harás con mi piel tan débil? escurridiza cincelo este abrazo que no me sacudo

regálame otro y otro y un poquito de otro más

$\&$

IV

vamos a asolar la urbe cómplice neblina sin cuerpo del delito

arrullemos la fuga/ fundo mi pueblo en tu territorio

y entro acurrucada desde antes hasta tu abrazo

tu mirada nutrida alberga esta herencia que te brindo

mañana no comenzará su derrota nuestra conquista

surquemos la tierra/ diseminemos la fábula

al tiempo su inevitable pasar/ ilustres jirones de silencio vestimos 
agota la nostalgia el aliento de las mareas, tú y usted convoca estremecimientos

balanceándonos en la lejanía/ mi apetito no sabría carecer de usted/ de ti

de la piel escapan fracturas luminosas / trazo rumbos en geografía de nuestros vientres

colonos sueñan tierra virgen que descubrir

(del poema "peutun $\left.{ }^{23 \prime \prime}\right)$

$\&$

Del libro inédito Anabática

quien habla del fuego trae en su puño el anabático anhelo de arrancar quien habla de heridas revive al homicida que matamos a piedrazos porque no queríamos verdad/ no quisimos que entrara y robara porque sabíamos que esa mirada y ese silencio es un monstruo que aguarda

y ya sin fuerzas

tan pequeñas

nos quitaron las ropas

y nos dijeron shhh... no le cuentes a nadie

y accedimos

y nos excitamos del modo horrible de las vírgenes violadas /

las vírgenes que lloran sangre/

yo tuve infiernos cariña/ estuve a piel abierta

y tocaba mi piel y no dolía

porque mi padre dijo que si te quemas dos veces ya no duele

y no dolió

Mariela Malhue (Santiago, 1984), poeta de origen mapuche ${ }^{24}$. Estudió Pedagogía en Castellano en la Universidad Metropolitana de Ciencias de la Educación (UMCE). En el 2008, realizó un diplomado en Estética y Filosofía en la Universidad Católica y un Seminario de Política y Literatura en el Centro de Análisis Político (CAIP). Ha participado en lecturas poéticas en Santiago y Valparaíso. El año 2008, fue invitada al encuentro de poesía "Riesgo País." Reside en Santiago.

Del libro inédito Estancia y doméstica

Yo estoy en la puerta y miro

Estoy en el canto de la puerta

por donde mi frase no amamantará el desasosiego 
Yo estoy en la puerta y miro

La Casa no dirá su nombre ni su raza

Yo estaré quieta en la puerta

escupiendo caligramas quietos

Mi eje no será repentino

Los brotes se desdicen de improviso

y el parque lo sabe al igual que la Casa

La complicidad se ha dibujado de tantas maneras

pero no hay manera y no hay forma

y no hay modo y no hay casa

$\&$

esta topografía es la única posesión que me toca

el pequeño territorio expropiado

mi topografía el porvenir secreto

un conjunto vacio este hogar

el día no me había nada

yo era su prisionera él el gran homicida

yo su prisionera y de rodillas me tuvo

sin algarabía

como la mártir pero sin contorciones

por eso limpiaba sus pieles yo

la piel de su suelo su techo el pasillo

limpiaba bajo amenaza la placenta me amancillaba

me envolvía le daba el pulso a mi voz

por eso establecí el tiempo fuera de los contornos

el homicida y todos sus nombres

Gabriel Tu Nombre Figura de Yeso Casa

y Tu Nombre en mi asfalto

se borra de tantas barridas

regar y barrer

limpiar el ruido abultado de las canaletas

escribir con virutas mis sonetos deformes

escribir en el ripio invisible/mi obscenidad

siempre disimular ante tu furia Casa

siempre disimular que sé decir

siempre disimular como una higiene que me preña

dibujar la limpieza como un matiz

acabar el simulacro

destemplar el rol

caer la gran máscara 
me muere la Casa en su monólogo

desvaría los escenarios del quehacer

ejecuta sus fuerzas de inteligencia contra todos estos

mis órganos

y yo caigo hemorragio le mancho la cara mi sangre

saturo todos sus conductos

absuelvo su sonido enumero ante ella la vacía la dueña de casa

ante esa la de puertas adentro

enumero -las butacas

el salón

un espejo contra otro

$\mathrm{y}$ yo en medio enumero

ella sabe a pesar que somos un puro conjunto de trozos

Casa cáeme tu gran máscara

$\&$

¿y si soy poiesis, si soy matriarcado?

¿quién cruzará la calle con mi rostro?

porque mi cara es un mosaico de dialectos ilegibles

entonces yo no diría palabra ni tormento

vería contornos caer con la cadencia rota

Te llamas ínfimo Figura de Yeso

yo repito tu nombre Repito distancias y dialectos

mi rostro bajo un velo magro

no traerá el delirio a esta urbe de mi Casa

entonces yo no habría danza en tu nombre

Yo no habría tu nombre en el eco de los murmullos

que se aglomeran en las preguntas que hago

esas preguntas antes del día

desde el pasillo en insomnio

oyendo la música de las bisagras yo oigo esa música

que es insomnio en mis oídos

la casa abrumada de azul y gris

tanto no puedo leer sus olores

\section{Español de América}

Descubrimiento de América establece tus jirones en los libros no la lengua española vació los ríos de los ojos los guacamayos todos vestiditos con su fulgor yo vi 
pero cómo sé cuéntame esta noche la historia

cuéntame del tsotsil ${ }^{25}$ del náhuatl ${ }^{26}$

sus hecatombes cosmogónicas

La mamá no está en la tribu no

su hijo árbol Amazonas escuchas ahora el español

y dónde está tu tsotsil tu náhuatl

Llegaron los grandes barcos flotas tiránicas extremando un tormento oculto

están desnudos sus pechos morenos sus penes morenos veo yo qué

veo juncos veo un cobertor verde en torno al lenguaje

el aire es verde también

pero el idioma español viene las flotas tormento

Guarda bien secreto nuestro guaraní y sus historias

la nutria y el guacamayo oigo llaman

Ellos saben ya las pieles blancas con su español de recambio

Nuestros colores no sabremos esconder

El maíz en los arreboles

La lluvia sobre nuestras fecundas vulvas

Ellos tienen ese color del elote del maíz sobre su cabello en español

$Y$ todo lo que traen es en español

En Chubut tejeré los estambres las ovejas dirán que sí

Y sabremos estar atentos a esas flotas

Te llamo con mi caracola de nácar

Mi música por el viento por el viento

La lengua en secreto en el estambre del sur

Esto sí es el sur y solo verde atraviesa mi Amazonas yo veo el sol

Yo veo las lenguas corazón de ríos selvas orales

La tierra blanda veo y lamo y siento yo

Yo Amazonas sol verde

Las raíces expanden todo su eje

Dime de su eje dime el sabor de esas raíces

Descubrimiento de América no en español

No en castellano

No en andaluz

No en cristóbal

Adriana Paredes Pinda ${ }^{27}$ (Osorno, 1970), profesora de Castellano y poeta de origen mapuche-huilliche. Un gran número de sus poemas han sido publicados en revistas y antologías. El año 2005 publica $\ddot{U} i^{28}$. Estudió el Magíster en Literatura Chilena e Hispanoamericana en la Universidad Austral de Valdivia. Actualmente vive en una comunidad en Riñinahue ${ }^{29}$, comuna de Lago Ranco en la Región de los Lagos. En estos momentos, prepara su segundo libro, Parias. 
Fue la lengua castellana que nos ultrajó en primer lugar y en último (la lengua y el pensamiento), pero no sólo ella por supuesto, la lengua hispana nos ha violentado, lo confieso, nos ha socavado, por eso escribo; la lengua castellana me ha perdido, sin retorno tal vez, me ha mordido los pensamientos y yo "pecadora," pobre de mí, me he enamorado de la lengua castellana meretriz, me ha robado el mapuzungun ${ }^{30}$, me ha robado el chezungun el ce sumun ${ }^{31}$, me ha robado el espíritu, el aliento, el sentido, me ha robado a Kallfv Llanka Lican ${ }^{32}$, me ha robado el lican, por eso escribo bajo estado hipnótico y no logro zafarme; esta lengua meretriz me pesa, me quema, esta weñefe ${ }^{33}$, este pensar weñefe de mí...

(de “De por qué escribo... Mollfvñ pu nvtram")

Del libro inédito Parias

\section{Mi destino}

untar el corazón de mis abuelas

con sangre de negros carneros

prenderme

de plata

titilando entre niebla y aura

los fvtakechem ${ }^{34}$

levantados

por el pálpito de un beso.

Grita mi nombre

en lo alto de la noche-dijeron

y me quedaré contigo

aunque

muerte

sea ungida

Sin embargo, nací

con las yemas

balbuceantes

sin la moneda de la sangre pura

que expiara todas mis transgresiones

y amansara el lomo de las azuladas madres.

La lengua rosada pulpa de ignominia y tempestades

no prescribe

he sido condenada a desgarrarme, rewe ${ }^{35}$ entre las páginas. 
Qué somos

sino

parias

villanos

desgarrados

sin el tatuaje de la eternidad.

Que no me sienta madre

que no me encienda

el soplo

del metawe ${ }^{36}$

que muda

mi lengua paria en aleteo y mordisco

me puja los códices que desdicen mi nombre

Ah lengua mísera de mí

si no te tuviera

sopla

sopla

que has de danzar tu recuperada

casta

de soterrados ecos

pendiéndose

en los molares

florecientes

de Filipa, mi tatarabuela

que mi lengua ha de salirse de sí misma

y pactar con el wekvfe ${ }^{37}$ que la ampara

su reverberación de pájaros y aromas

que mi lengua ha de partirse

-ha de partirse- dicen

por porfiada y lujuriosa

te recuperaré

y mi lazo

rodeará acaso el aura de tus sílabas magnolias

ah mi pinda lengua

lengua mía y de todas sin misericordia

$\&$ 
amor mío del camino del ancestro

-eluen ñi piwke yem-pian ${ }^{38}$

retórname mi corazón -te digo

dónde se halla -le pregunté

a la estrella nodriza

de los sueños de los parias

mas guardó silencio...

está aquí mi corazón? -le dije al trueno

y su sonido llenó el mundo

cuándo fue que tus ojos se extinguieron a mi luz?

ya no hay danza

posible

en la deshabitada sílaba

de mi piel sin resuello

ah si mi lengua pinda

tan sólo encallara

pero ella medusa errante

chew mvley neyen ${ }^{39}$ insiste

toda ciega manca celestial

y ya no soy la que vibra en la caña de los bosques

la que corre raptada por el pangui ${ }^{40}$

en awvn $^{41}$

ya no soy sino la otra desmedida

"entre el cielo y la tierra"

mi tatarabuela

brotando de su molar prodigioso

Filipa la que vuela con las manos

suele acariciarme

la nieve de los párpados

entonces

abuela-retórname mi corazón -le digo

pero ella la otra

ecos en la niebla

y tú sin embargo sigues siendo el que no conoce la muerte

$\&$

No hay lican dentro de mí -te dije

es que no hay lican posible 
sino destello

el hallazgo

en su lengua, inconmensurable

llagada pulpa lengua

de amores desterrada

me quedaré contigo -te proclamo

en la resonancia del brote tierno de la quila

me quedaré, yo la otra

a galope de mi corazón vuelto cenizas

me quedaré contigo

cuando te trices

en el gélido capullo de mi cuerpo

descarnado

mi lengua menguante pedernal

azul

del aliento

ensillando su derrota

ah mapudungolu ta inchin re dugun ${ }^{42}$

ecos en la niebla

hermana mía

que no hay quien borre mi nombre despreciado

Liliana Ancalao ${ }^{43}$ (Comodoro Rivadavia en la Patagonia argentina, 1961). Es integrante de la comunidad mapuchetehuelche "Namkulawen." 44 Es profesora en Letras e integra el grupo universitario de investigación de mapuzungun. Su poesía ha sido incluida en diferentes antologías americanas, patagónicas y comodorenses. En el año 2001 publica su primer libro Tejido con lana cruda. Reside en Comodoro Rivadavia.

Del libro Tejido con lana cruda (2001)

otra mudanza interrumpe los latidos

con sus tacos golpea los rincones

me va quebrando el techo

me señala

(del poema "mudanza") 


\section{pregunta}

habrá que resignarse a ser pregunta arremangarse los pies

seguir andando

con un golpe de sismo por espalda

sin cimientos

ni contemplaciones

habrá que acostumbrarse sin respuesta

morir en una historia y otra historia

salir de madre pateando las preguntas

por los caños de la piel

hasta los huesos

y andar

humano no más

apuntalando luchas

controlando

el pulso de la tierra

mirarse escombro en el mapa de los sueños

$\&$

detrás de los párpados queda la vigilia detenida

en el sueño un haz de luz centellea

y sospecho

que un paso más acá están las respuestas

(del poema "detrás de los párpados")

esta voz

ella respira en la membrana

de un tambor remojado en la garganta

desde la piel de cueros costurados

hasta la aguada de los teros

lejos

a veces

cuando pienso en las alturas

soy un cóndor que se arroja contra el frío

arrancándose las alas en el filo de los pinos

y los volcanes se hacen llamas en los dedos

y me truenan los potros torturados en las

venas 
y esta voz

que es cenizas en los labios

pretende ser cascada en el desierto

desde la sangre caer mi llanto

gritar

hasta el abismo del silencio

$\&$

el viento siempre vuelve

quiere rendirnos a nosotras

probarnos las raíces

llevarse algunas

arrastradas

o girando

yo prefiero esas matas livianas

a estos huesos espesos

que reventarán por el cemento

era madrugada y efemia despertó

con la helada en el pelo

y el frío esa vez tenía boca

y se reía con nosotras

se está poniendo viejo el frío nos decían

las mujeres aprendemos

tarde

que hay un tiempo en la vida

en que hasta sin intención

vamos dejando una huella de incendio

por el barrio

ni sé por qué la perdemos

y esa tarde yo precisaba

medias de lana cruda para cruzar la calle

(del poema "Las mujeres y el viento") 
Cecilia Nahuelquín Nahuelquín ${ }^{45}$ (Valparaíso, 1963). Artista visual, artesana y poeta. Es presidenta de la Asociación de Mujeres Indígenas de la V Región, "Taihuel."46 Sus poemas han sido publicados en diferentes revistas en Chile. Se asume como mujer "mapuche urbana redimida" y reside en Valparaíso.

Del libro Hui ${ }^{47}$ (2006)

No soy mujer letrada sólo escribo lo que pienso no busco gloria ajena sólo digo lo que siento.

Soy como un ave que nadie le pide que cante y lo hace de igual forma sólo para expresarse.

Wirife domo ngelafun

Ni rakiduamün müten wiriken Kakeche ñi sakiñ kintuyawlan Ñi dungu müten feipilen

Üñüm rekelen

Inei rume ülkantunge pikelaeyeu

Kisungünewün femkeingün

Adngen ñi piael müten

$\&$

Desierto,

El canto se hizo suave

Y un hielo sentí en mi espalda

Porque vi más abajo,

En el suelo sagrado,

Unos arroyos profundos.

Eran sepulcros de restos óseos inundados

De sus abuelas y abuelos...

También estaban los míos.

Chengerkenun

nochiluwi chi ülkantun 
ta ñi furi mew wütre akui

fei ñi nagkintupan fachi

mapu mew

füta lewfü reke amulei ti witrunko.

Ingaf amurkei püle ti ko

ñi kuifike futake che yem...

Ñi pu che ka ülenkepingen fei ti mew

(del poema "Desierto" / "Chengerkenun")

$\&$

En un lenguaje sencillo te muestro,

es mi cuento en la urbe,

dijo mi amiga Colomba,

que haya nacido en este lugar de la tierra

hija de madre huilliche

y de un wingka sin conciencia.

Re dungumew pengelelayu

tañi waria dungu tati

feipienew ñi weni Colomba

fachi mapu mew mi choyün

williche ñuke ñi puñeñ

wingka ñi ngenoduam

(del poema "Cuando me llamaba la trutruka" / "Mütrümetew trutruka") 
María Huenuñir ${ }^{48}$ Antihuala $^{49}$ (Cayumapu Alto, 1968), poeta mapuche. Su primera incursión en la poesía se inició en un taller de la comuna de Lo Prado, con el patrocinio de PRODEMU, en las organizaciones mapuche. Junto a sus compañeros, se editó un pequeño libro llamado Cuentos de la tierra, cuentos de la vida. Luego, publica el libro Malen Mapu/ Niña del Campo apoyada por una ONG, libro que tuvo una edición limitada. En 2004 publica Más allá de ser Mapuche (con una segunda edición en 2008). Fue invitada para el año 2009 a dar clases de mapuzungun en la Universidad Nacional de Rosario, Argentina. Reside en Santiago.

Del libro Más allá de ser Mapuche (2004)

Kom ñi pu trenqueque

umauteigun

welu ñi peuman meu

wepeaigun.

Todos los ancianos ya se han dormido pero en mis sueños hoy, yo los despierto

$\&$

\section{El Rewe}

Yo quiero hablarles del Rewe.

Como un altar sagrado, donde se posa la machi, a rogar, por los enfermos.

Este debe ubicarse, siempre de frente al Sol, porque, cuando amanece, se llena la bendición.

¡No es un palo cualquiera! ni se talla por afición, es de sagradas maderas y se fabrica por petición. No se muestra, "donde quiera," si se respeta la tradición y para que no se pierda, queda al cuidado de Dios. Cuando el Rewe se entierra, 
se hace una ceremonia*

y por respeto se bautiza,

con la bebida* sagrada.

*Ceremonia sagrada: NGUILLATUN

*Bebida sagrada de Trigo, Maíz o Piñón: MUDAY50

$\&$

\section{El Kulxun}

El Kulxun es muy sagrado, no lo toca cualquiera, es solicitado en sueño, porque simboliza la tierra. Cuando ya tiene un dueño, pasa a ser divino,

porque guarda los secretos de un arte único.

Cuando su dueño fallece, es mejor destruirlo, pero; no en cualquier parte éste, se bota al río.

El horario preciso, es siempre en atardecer, porque se queda dormido, lo que se llama poder.

Allí la corriente del agua junto a la puesta de Sol, se llevan la energías, de regreso al creador. Las fuerzas encerradas, son liberadas en el mar, entonces, se quedan perdidas, dormidas por la eternidad.

*KULXUN o KULTRUN: instrumento diseñado en madera y cuero. Es usado principalmente por las machis..$^{51}$

\section{Tejer sueños ancestrales}

Yo enhebro mis palabras, para tejer unidad, por el hilo de la vida, también me quiero enhebrar.

Si mi alma está dolida, 
mi voz prefiere cantar, para cicatrizar la herida, de la que les quiero contar. Yo soy hija de la tierra, Mi padre es el astro Sol ijuro que no es mentira! soy hermana del dolor. Mi raíz está marcada, sobre doradas praderas está entrelazada como fértil enredadera. Donde florece el copihue, allá donde crece el pewen, donde, germina el bosque y donde, semilla el lawen. ¡Allá lejos! Yo canto para que me escuche el mar, yo proclamo a los vientos, que me puedan escuchar. Van los ecos melodiosos gritando que soy la miez, van suplicando piadosos pa' que yo me sienta bien.

\section{Notas}

1 Académica Universidad de Santiago de Chile.

2 Los llamekan corresponden a cantos exclusivos de mujeres y los machi ül, son los cantos de machi.

3 Curriao: oscuro y salvaje.

4 Pewenche: gente del pewen o pehuén (araucaria). Mapuche que habitan en las zonas andinas del sur de Chile.

5 Perrimontún: es una de las tres posibilidades por las que una persona puede ser llamada a convertirse a machi. Corresponde a visiones y experiencias, en general acerca de catástrofes de la naturaleza, que le ocurren a esta persona, la que puede ser mujer $u$ hombre.

6 Kupalme o kupan: linaje, origen familiar.

7 Kutrlawe: fuego, fogón.

8 Colipe: de Kolipe, pluma (pichón) rojiza (koli).

9 Nancuvil: de Namkuvil, serpiente (vilu o filu).

10 Gineo: según Maribel Mora, no tiene claro "si sería un nombre adoptado de otra cultura o se habría deformado tanto al pasarlo 
al español, que resulta difícil saber qué significa. En todo caso, la comunidad mapuche de la que proviene una de las ramas de mi familia materna, por parte de mi abuela, se llama José Ginea Ñanco, cercana a Temuco. Se dice que, quizás lo de neo sea apócope de nahuel (especie de leopardo...), pero gi, por sí solo, no hay cómo traducirlo." En conversación virtual con la poeta, el día 6 de enero de 2008.

11 Chiguay: de Chiwai, neblina.

12 Treng Treng y Kai Kai: corresponden a las serpientes de tierra y de agua, respectivamente. Seres míticos que libraron una fuerte lucha en tiempos muy antiguos. Kai Kai hizo crecer las aguas y Treng Treng aumentó la altura de los cerros para que en ellos los mapuche se refugiaran y salvaran del diluvio. En cada comunidad mapuche hay un cerro llamado Treng Treng que rememora este lugar inaugural de la cultura.

13 Lican: de Likan, hace referencia a ciertas piedras pulidas, generalmente de color negro, consideradas con potentes poderes. Estas piedras son utilizadas por la machi en sus trabajos rituales.

14 Tuwin Malen: Tuwin o Tüwün, lugar de origen territorial y también del conocimiento y la espiritualidad. Malen, muchacha, mujer.

15 Machi: persona con capacidades de sanación (chamán).

16 Meulen: cierto tipo de viento arremolinado.

17 Sumpall, Shumpall o Chumpall: ser mítico que habita las aguas. Se aparece como un hombre joven de cabellos dorados y vestiduras resplandecientes. Habita en lagunas, ríos y mares en donde seduce y rapta a mujeres mapuche, a quienes toma como esposas. En ocasiones paga por ellas con bienes de sus propios dominios.

18 Rupailaf: el y/o la que atraviesa el mar.

19 Huilliche, williche o veliche: gente del sur. Rama meridional de los mapuche que habita en toda la Décima Región de Chile.

20 Coñuecar: poblado de gente joven y/o pueblo de guerreros.

21 Ivonne Coñuecar ha manifestado que ella se siente "poeta del mundo," por lo que no se vincula preferencialmente a la producción de poesía mapuche. Sin embargo, al mismo tiempo, afirma que ella, sin duda, tiene un origen huilliche, por lo que en muchos de sus poemas se evidencia un sustrato cultural mapuche.

22 Eluwun: ceremonia de entierro, funeral.

23 Peutun: volver a encontrarse, hallar lo perdido.

24 La poeta considera que su escritura, no se sitúa "estrictamente" desde una perspectiva cultural mapuche, pero sí, asume su origen mapuche. La misma autora afirma: "Sobre si me siento una mujer de origen mapuche... sí, sí reconozco el origen mucho más evidente en mí... (pero) Es como ser una hija no reconocida, una huérfana de raíz.." Conversación mantenida con Mariela Malhue el día 10 de diciembre de 2008. 
25 Tsotsil: lengua de personas indígenas de los Altos de Chiapas.

26 Náhuatl: lengua de los Nahuas (Aztecas), deriva de nahua-tl, sonido claro y agradable.

27 Pinda: picaflor.

28 Üi: el nombre más antiguo de una persona. Antiguamente era su real nombre y todos los mapuche tienen uno, pero no es necesariamente el que llevan. Es como la respiración de cada persona, el aliento, es su ser.

29 Riñinahue: cola de tigre.

30 Mapuzungun: de mapu, tierra y zungun, lengua y/o palabra. Entonces, lengua o palabra de la tierra. Corresponde a la lengua de los Mapuche.

31 Chezungun o ce zumun: lengua de los Huilliche.

32 Kallfv Llanka Lican: piedra azul luminosa.

33 Weñefe: ladrón/a, robado.

34 Fvtakechem: abuelos que ya partieron, todos los ancestros que una y otra vez vuelven a nacer de los cuatro abuelos originales: Kvse, Fvcha, Weche, Vlcha (anciana, anciano, joven hombre, joven mujer) y han reactualizado su nombre en la tierra. Los ancestros son fvta porque son grandes en su saber y en memoria.

35 Rewe: árbol sagrado de la o el machi. Es un tronco de laurel, maki o canelo que se planta en el suelo y se adorna con colihues y otras plantas. Tiene entre cuatro y siete peldaños que simbolizan los niveles del mundo espiritual mapuche.en ciertos rituales la machi, en estado de trance, suele subir por dichos peldaños para establecer comunicación con espíritus superiores y antepasados.

36 Metawe: vasija de greda de diferentes formas.

37 Wekvfe, wekufü o huecuve: es el espíritu, la fuerza o energía negativa, que provoca desastres, enfermedades y muerte.

38 Eluen ñi piwke yem- piam: devuélveme mi corazón antiguo- te digo.

39 Chew mvley neyen?: Dónde habita el aliento?

40 Pangui: puma.

41 Awun: trilla a caballo que consta de cuatro vueltas completas alrededor del campo ceremonial con el fin de saludar y complacer a los cuatro espíritus creadores (abuelo, abuela, joven mujer y joven hombre). Finaliza en el lado oriente hacia la salida del sol, allí se termina con una oración.

42 Mapudungolu ta inchin re dugun: sólo en mapudungun hablamos nosotros la pureza de la lengua.

43 Ancalao: cuerpo de mar.

44 Namkulawen: Namku, especie de águila y lawen, remedio, hierba medicinal. Entonces, remedio de águila, el que tiene connotaciones positivas.

45 Nahuelquín: linaje de tigre (o más bien de un tipo de leopardo). 
46 Taihuel: cascada del cielo.

47 Hui: “...una suerte de rito lúdico donde ella (la madre) expulsaba toda su tristeza al viento del sur. De pie frente al sol o bajo lluvia, descalza y con los brazos abiertos, daba vueltas gritando ¡huiii! Hasta marearse y caer rendida y redimida al suelo. Una verdadera liberación del espíritu; la experiencia más deliciosa que una niña mapuche huilliche pueda experimentar escondida en una isla de Chiloé." En Cecilia Nahuelquín, El Hui. Cantos de libertad de una mujer mapuche en Valparaíso (Valparaíso: La Cáfila, 2006), p. 5.

48 Huenuñir: zorro en altura o zorro de lo alto.

49 Antihuala: Pato del sol.

50 Referencia señalada en el libro por la misma poeta.

51 Idem.

\section{Bibliografía}

Ancalao, Liliana. Tejido con Lana Cruda. Comodoro Rivadavia: Ediciones de Autor, 2001.

Catrileo, María. Diccionario Lingüístico-Etonográfico de la Lengua Mapuche. Santiago: Andrés Bello, 1995.

Coñuecar Araya, Ivonne. Catabática. Valdivia: CONARTE, 2008.

----- Anabática (inédito).

Huenuñir Antihuala, María. Más allá de ser mapuche. Santiago: HS Imprenta, 2004.

Huenún, Jaime. La memoria iluminada: poesía mapuche contemporánea. España: Centro de Ediciones de la Diputación de Málaga, 2007.

Nahuelquín Nahuelquín, Cecilia. El Hui. Cantos de libertad de una mujer mapuche de Valparaíso. Valparaíso: La Cáfila, 2006.

Miranda Ruaplilaf, Roxana. Pu llimen ñi rulpázuamelkaken/ Seducción de los venenos (en prensa, Lom Ediciones).

Mora Curriao, Maribel. Perrimontun (inédito).

Paredes Pinda, Adriana. Üi. Santiago: Lom Ediciones, 2005.

----- Parias (inédito). 